\title{
RELIGIÓN Y ESPACIO PÚBLICO: EL CONFLICTO EN TORNO A LA REGULACIÓN DEL VELO INTEGRAL ISLÁMICO
}

\section{Religion and Public Space: The Conflict about Islamic Face Veiling}

\author{
Mar Griera*; Marian Burchardt** \\ * Universitat Autònoma de Barcelona; ${ }^{*}$ Max Planck Institute for the Study of Religious and \\ Ethnic Diversity (Alemania) \\ mariadelmar.griera@uab.cat; burchardt@mmg.mpg.de
}

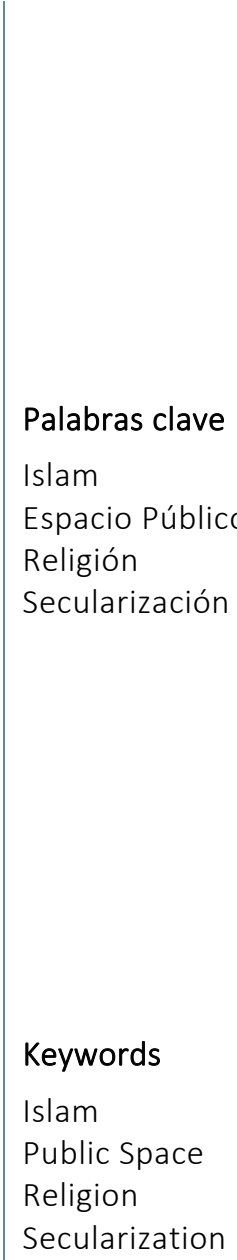

\begin{abstract}
Resumen
En la última década la cuestión del velo integral ha generado acalorados debates políticos en numerosos países europeos y ha sido objeto de una creciente regulación jurídica a nivel europeo, estatal y local. A partir de un estudio de caso, este artículo se centra en analizar en profundidad los procesos de problematización y regulación legal del velo integral en Cataluña. El objetivo es examinar las razones que explican la emergencia de esta problemática y analizar de qué manera se construyen los argumentos que apoyan o desaprueban la regulación local del uso del velo integral en el espacio público. El objetivo es comprender cómo los discursos en torno a la laicidad y la religión en el espacio público se traducen en posiciones concretas, y cómo se configuran, articulan y confrontan diferentes concepciones sobre el significado, y los límites, de la libertad religiosa en el contexto de ese conflicto. El artículo concluye afirmando la necesidad de ubicar el conflicto más allá de la cuestión religiosa y entenderlo, también, como consecuencia de la naturaleza excluyente del espacio público contemporáneo y la creciente regulación de sus usos.
\end{abstract}

\section{Abstract}

This article focuses on the rising controversies about religious symbols, in particular the debates about the prohibition of the Islamic full-face veil (burka, niqab) in public space. Starting from the case of a Catalan city, we examine the sources of this controversy at the local level and analyze the discourses mobilized by different actors in the field. Through the empirical analysis, we scrutinize how discourses on religious freedom and secularity are articulated with particular notions of public space to frame this specific conflict. The analysis shows that the rise and the evolution of these controversies must be situated beyond the religious-secular binary, and that this confrontation cannot simply be read as a consequence of a presumed opposition between Islam and the secular state. Therefore, while the majority of existing studies examines the (lack of) compatibility of the full-face veil with certain concepts of secularity, we show that different concepts about public space and its uses are a much more promising starting point for understanding conflicts about face-veiling.

Griera, M., \& Burchardt, M. (2016). Religión y Espacio público: el conflicto en torno a la regulación del velo integral islámico. Papeles del CEIC. International Journal on Collective Identity Research, vol. 2016/2, papel 159, CEIC (Centro de Estudios sobre la Identidad Colectiva), Universidad del País Vasco, http://dx.doi.org/10.1387/pceic.16190 


\section{INTRODUCCIÓN}

En 1965 el teólogo norteamericano Harvey Cox publicó el ensayo The Secular City, un libro que, en pocos años, se convirtió en un bestseller muy popular entre estudiosos de la religión y otros científicos sociales. Para Cox los procesos de urbanización iban parejos a la secularización de la sociedad y la emergencia de la ciudad moderna marcaba el inicio de la pérdida de relevancia social de la religión.

Hoy, cincuenta años más tarde, el veredicto de Cox sobre la secularización de la urbe contemporánea es difícil de sostener. En las últimas décadas se han multiplicado exponencialmente las aportaciones académicas que nos muestran la vitalidad de la religión en la sociedad contemporánea. En esta línea, Peter Berger (1999) ha argumentado que nos encontramos frente a un proceso de desecularización de la sociedad, a la vez que ha enfatizado que, a diferencia de lo que predijeron los científicos sociales tiempo atrás, aquello que caracteriza la sociedad moderna no es la secularización sino el pluralismo. En un sentido similar, el sociólogo José Casanova (1994) ha señalado la creciente importancia pública de la religión y los procesos de desprivatización de la misma. Desde otro prisma, filósofos como Jürgen Habermas (2006) han analizado y puesto en consideración la compatibilidad entre la democracia moderna y la razón religiosa en nuestra sociedad contemporánea.

Las ciudades son, cada vez más, cuna de una creciente diversidad religiosa. Las migraciones internacionales y la movilización de las identidades religiosas en la esfera global contribuyen a incrementar la visibilidad de las comunidades religiosas en el espacio urbano. Esta creciente visibilidad favorece la emergencia de nuevas controversias como son las polémicas en torno la construcción de nuevos lugares de culto (Astor, 2014), los debates sobre los procesos de acomodación de la diversidad religiosa en instituciones públicas (Griera, Martínez-Ariño et al., 2015) o los conflictos en torno a los símbolos religiosos. Unos conflictos en los cuales cristalizan y se confrontan identidades religiosas y seculares y posiciones ideológicas de cuño muy distinto.

Este artículo se centra en una de estas controversias que es, concretamente, el debate y la regulación sobre el uso del velo integral popularmente conocido como burka o niqab- en los espacios públicos. En la última década la cuestión del velo integral ha generado acalorados 
debates políticos en países como Francia (Selby, 2011) o Bélgica (Fadil, 2014) y ha sido objeto de una creciente regulación jurídica y política tanto a nivel europeo, como estatal y local. En el contexto catalán el conflicto del velo integral ha tomado una especial virulencia y más de 10 municipios han impulsado regulaciones específicas para prohibir su uso en el espacio público, mientras que otros muchos han discutido la cuestión en los plenos municipales (Burchardt et al., 2015). En cierto modo, la regulación del velo integral, junto con las problemáticas en torno a la apertura de centros de culto (especialmente islámicos), han sido los temas más polémicos en la gestión local de la diversidad religiosa en Catalunya (Astor, 2014). Ahora bien, resulta importante constatar que, a diferencia de la cuestión de los centros de culto, la problemática del velo integral afecta a un número muy limitado, casi anecdótico, de personas. Contrasta, así, el grado de polémica suscitado con la dimensión real del fenómeno en la actualidad en Catalunya.

El objetivo de este artículo es examinar las razones que explican la emergencia de esta problemática y analizar de qué manera se construyen y movilizan los argumentos que apoyan o desaprueban la regulación local del uso del velo en el espacio público. La pregunta que impulsa la investigación es comprender porqué se produce la necesidad percibida de regular esta cuestión desde la esfera local, y cuáles son los argumentos que se movilizan para justificarlo. La voluntad es comprender cómo los discursos en torno a la laicidad y la religión en el espacio público se traducen en posiciones concretas, y cómo se configuran, articulan y confrontan diferentes concepciones sobre el significado, y los límites, de la libertad religiosa en el contexto de dicho conflicto. Con este propósito, analizaremos los imaginarios, las ideas y los sentimientos que se movilizan en los discursos públicos sobre el velo integral y que lo convierten en un "problema social".

Hasta el momento, son casi inexistentes los estudios que analizan las controversias sobre el velo integral desde una perspectiva empírica. Los científicos sociales tienden a asumir - a menudo incorrectamente, como argumentaremos- que los debates sobre el velo integral son, en gran medida, una prolongación de los debates sobre el hijab. Desde esta perspectiva, la mayoría de autores se centran en analizar y discutir la dimensión filosófica-normativa de estas nuevas regulaciones en continuidad con la amplia bibliografía existente en torno al hijab (Joppke, 2010; Amirian y Zain, 2009). La mayoría de las investigaciones, 
además, toman una perspectiva estatal y se focalizan en su vertiente legal (Grillo y Shah, 2012; Motilla, 2013; Ferrari y Pastorelli, 2013), con lo cual obvian el análisis de los procesos de construcción social de la problemática que emergen de la esfera local.

El artículo se basa, principalmente, en un estudio de caso realizado en la ciudad catalana de Reus, donde el 18 de julio de 2014, el Ayuntamiento aprobó una ordenanza municipal de civismo con el fin de regular y prohibir una serie de prácticas consideradas "no deseables" en el espacio público como la desnudez, las formas visibles de prostitución, la mendicidad o el porte del velo integral. El trabajo de campo se desarrolló durante 2014-15 a partir de la realización de entrevistas semiestructuradas a los principales actores políticos y sociales que intervinieron en la controversia. Dos de los entrevistados eran militantes del Partido Popular y de Convergencia y Unión que se habian posicionado claramente a favor de la prohibición; otro era el secretario jurídico del Ayuntamiento de Reus; otros tres pertenecían a la asociación Carrutxa que se dedica a la organización de fiestas populares y a la protección del espacio público; una era la representante de la organización Amnistía International que se dedica a la defensa de los derechos humanos; y dos eran militantes del partido Candidatura d'Unitat Popular (CUP) que se posicionaban en contra de la prohibición. La selección de los actores entrevistados se hizo teniendo en cuenta su papel en la construcción del discurso público y político sobre la temática ${ }^{1}$. Asimismo, también se analizaron los debates en los plenos, los informes jurídicos realizados y la cobertura mediática. El análisis se complementa con la información extraída de una investigación paralela sobre la regulación del velo integral en la ciudad de Lleida (Burchardt et al., 2015). En el caso de Reus se realizaron, transcribieron y analizaron 8 entrevistas y 14 por el caso de Lleida. En este artículo usamos tanto la cobertura mediática como información contextual y nos enfocamos en la presentación de los resultados del análisis de las entrevistas.

El artículo se organiza en tres secciones. En una primera parte, se explicita la aproximación teórica. En una segunda parte se expone el contexto de la problemática. La tercera parte se centra en analizar las

\footnotetext{
1 Es por esta cuestión que, y a pesar que hubiera sido muy interesante, no se incluyó en la muestra las personas que eran objeto de la regulación -es decir, las mujeres portadoras de velo integral- ya que su voz fue negada durante todo el conflicto.
} 
posiciones de los actores y las razones detrás de la movilización. El artículo termina con unos apuntes finales a modo de conclusión.

\section{RELIGIÓN, ESFERA PÚBLICA Y ESPACIO PÚBLICO: APROXIMACIONES TEÓRICAS}

Dos tradiciones teóricas abordan la relación entre la religión y lo público: en primer lugar, la literatura sobre la esfera pública, que se inspira principalmente en la filosofía política liberal, y la teoría crítica. En segundo lugar, la literatura sobre el espacio público, que surgió a raíz del giro espacial en las ciencias sociales y que incluye geógrafos, urbanistas y antropólogos entre sus principales colaboradores.

La primera corriente está representada, principalmente, por la obra de Jürgen Habermas. El filósofo alemán en su estudio clásico sobre la emergencia de la esfera pública (Habermas, 1962) insiste en que ésta es una expresión particular de la sociedad civil, que no permanece contenida dentro de ella, sino que surge de la interacción entre la sociedad civil y el Estado. Es con el surgimiento de la democracia representativa, el estado de derecho y el estado liberal que la preocupación por la esfera pública se ubicó al centro de pensamiento político normativo y la organización de la vida política. El punto de referencia normativo central es la justicia (González de Requena, 2012) y la cuestión religiosa es también examinada y evaluada desde esta perspectiva. En el campo de la sociología de la religión, la aportación principal en esta línea es la que realiza José Casanova en su libro Public Religion in the Modern World (1994). Casanova analiza los procesos contemporáneos de desprivatización de la religión, fijándose, principalmente, en la capacidad de las organizaciones religiosas para intervenir en la esfera pública. En los últimos años han aumentado las estudios que analizan el papel de la religión en la esfera pública (Arlettaz, 2015) así como los que analizan la configuración histórica de los discursos públicos y su construcción normativa (Díaz-Salazar, 2007). La mayor parte de la literatura existente sobre el velo integral se enmarca en esta línea de pensamiento y analiza la prohibición del uso del velo integral en el espacio público a partir de su articulación con los principios normativos que regulan la esfera pública en contextos democráticos (Ferrari y Pastorelli, 2013; Grillo y Shah, 2012).

Por otro lado, nos encontramos también con los estudios sobre el espacio público que, desde una perspectiva sociológica, lo abordan como un 
contexto dramatúrgico y lugar de sociabilidad. Nos referimos, especialmente, a las aportaciones del sociólogo estadounidense Erving Goffman. Las investigaciones de Goffman sobre el espacio público emergen de su interés por la investigación de las interacciones ritualizadas "cara a cara", sobre todo entre desconocidos. Desde su perspectiva, el espacio público se caracteriza por ser el reino de las interacciones ritualizadas gobernadas por lo que él llama la "rule of civil inattention" (o la regla de la inatención cortés). La vía pública se conceptualiza como el espacio donde todos nosotros nos comportamos siguiendo unos patrones determinados y prefijados; unos patrones que, a menudo, incluyen el hecho de evitar la interacción directa con "el otro presente", al tiempo que la voluntad de mostrar que no tenemos una intención hostil o disruptiva. En palabras de Goffman, "las calles de la ciudad proporcionan un entorno en el que la confianza mutua se muestra de forma rutinaria entre extraños" (Goffman, 1963: 17). Sin embargo, en determinados momentos se producen hechos $y / 0$ acciones que desafían el orden "normal" de la interacción, lo que obliga a renegociar el marco moral y de sentido que sustenta el orden público. El espacio público se diferencia del privado porqué está basado en dos reglas fundamentales, la del uso público y la libre circulación (Marrero, 2009).

Si bien hay algunos solapamientos entre la literatura sobre la esfera pública y el espacio público, también es importante señalar sus diferencias. Así, mientras la esfera pública se suele interpretar como un terreno discursivo, normativo y abstracto, la investigación sobre el espacio público se centra, principalmente, en la materialidad de los espacios y en analizar cómo cristalizan de forma concreta los usos y las prácticas que constituyen y encarnan el espacio público (Becci et al., 2016; Burchardt y Höhne, 2016). En este artículo partimos, principalmente, de esta segunda corriente teórica que concibe el espacio público como un producto tangible de las relaciones sociales concretas y formas de poder determinadas. Ahora bien, ambas perspectivas nos ayudan a examinar con mayor profundidad el tema de la investigación.

De este modo, por un lado, tomar la perspectiva de la esfera pública nos permite comprender la importancia de los imaginarios ideológicos y las representaciones político-normativas subyacentes detrás nociones como laicidad, secularización o neutralidad (Wohlrab-Sahr y Burchardt, 2012). La mirada contemporánea sobre el hecho religioso es deudora de una historia particular -especialmente convulsa en el ámbito español y catalán-que 
históricamente se construyó en torno a la disyuntiva $-\mathrm{y}$ la violenciaentre la Iglesia Católica y los agentes modernizadores (partidos progresistas, movimientos de librepensamiento). Esta dicotomía entre clericalismo-anticlericalismo ha influido notablemente en los imaginarios sobre la religión en el espacio público en España (Díaz-Salazar, 2007), si bien la transición democrática supuso un cambió sustancial en su configuración. Desde entonces, el marco normativo e ideológico se ha complejizado y han surgido nuevos ejes a través de los cuales pensar la presencia de la religión en el espacio público (mayorías/minorías; cultura/religión).

En segundo lugar, la literatura que se centra en el análisis del espacio público como un lugar material y concreto, nos ofrece herramientas para interpretar cómo la religión cristaliza en el espacio público y las respuestas que genera esta presencia. Es una perspectiva que promueve un conocimiento situado y basado en las acciones y los discursos alrededor de una expresión pública de religiosidad. Hemos hecho referencia a la obra de Goffman y a la importancia de comprender que el espacio público es un escenario ritualizado donde funcionamos según unos patrones prefijados que estructuran y vehiculan las interacciones. Nuestra percepción de seguridad y confianza pasa por el mantenimiento de estos rituales y de una serie de códigos implícitos. Es el seguimiento de estos patrones lo que hace que en la vida cotidiana podamos funcionar de manera "casi automática" (lo que Alfred Schütz (1974), siguiendo a Husserl, llama la epojé o suspensión de la duda). En cierto modo, los símbolos religiosos, a menudo, pueden ser concebidos como elementos disruptivos que ponen en cuestión momentáneamente el fluir "normal" de la vía pública. Desde esta perspectiva, éste es un motivo fundamental que nos permite entender porque a menudo despiertan animosidad entre la población (si bien también pueden generar sorpresa o atracción). El velo integral puede concebirse como una forma de ruptura y es pertinente estudiar cómo y de qué manera es percibida, explicada y contextualizada esta ruptura. Según Harold Garfinkel (1967), damos sentido a las disrupciones a través de lo que él llama el "método interpretativo documental" que nos ayuda a construir una interpretación concreta sobre una experiencia de ruptura. Esta interpretación se basa en nuestros conocimientos y experiencias previas $y$, generalmente la tomamos como muestra o prueba de un patrón subyacente $y$, a la vez, como evidencia para el mismo. Hecho que facilita que en su interpretación, reproduzcamos estereotipos de genero, clase o 
etnia $u$ otros presupuestos previos. Es decir, la forma de conceptualizar esta ruptura estará influida por nuestros posicionamientos ideológicos y los imaginarios de los que hablábamos antes.

\section{CONTEXTO}

Reus es una ciudad situada en el sur de Catalunya, en la provincia de Tarragona y tiene alrededor de 104.000 habitantes, más del $20 \%$ de los cuales son nacidos en el extranjero (IDESCAT, 2015). En Reus, la minoría más numerosa es la configurada por los marroquís $(43,06 \%)$, seguido de los rumanos $(17,08)$, los bolivianos $(4,6 \%$ y y los colombianos $(3,9 \%)$.

Los debates sobre la integración de los inmigrantes han estado en el centro de la escena política local en los últimos años. Son especialmente notables las largas y amargas controversias en torno a la apertura de espacios de culto islámicos. La primera mezquita local fue inaugurada en 1999 y provocó la protesta de los vecinos que argumentaron que la apertura de un lugar de culto musulmán haría aumentar la delincuencia y la sensación de inseguridad en la zona circundante ${ }^{2}$. A pesar de la polémica, la mezquita abrió sus puertas, pero pronto se hizo evidente que era demasiado pequeña para dar cabida al creciente número de población musulmana que vivía en Reus y que participaba a los rezos. Por este motivo, la comunidad intentó comprar o alquilar otro local. Sin embargo, durante la primera década de los 2000, cada vez que la comunidad musulmana trató de abrir un nuevo lugar de culto, los vecinos impulsaron protestas tipo NIMBY $^{3}$ y bloquearon el proyecto.

El conflicto tuvo episodios de especial virulencia, especialmente cuando los vecinos organizaron manifestaciones y asambleas públicas de protesta (en 2001, 2004 y 2011). Es importante señalar que el caso de Reus no es una excepción en la zona. Como el sociólogo Avi Astor observa, "en los últimos años los conflictos por la apertura de centros islámicos han sido frecuentes en España, y especialmente en Catalunya" (2011: 36). En cierto modo, esta problematización coincide con la mayor visibilidad de las minorías en el espacio público en los últimos años. El crecimiento de las migraciones internacionales ha favorecido una transformación relevante del mapa religioso catalán, hecho que ha impulsado una mayor atención pública y

\footnotetext{
${ }^{2}$ Ver: http://elpais.com/diario/2004/01/12/catalunya/1073873246_850215.html. Última consulta: 15/01/2015.

${ }^{3}$ Las siglas significan "Not In My Back Yard" que se puede traducir como "No en mi patio trasero".
} 
política hacia la cuestión (Astor 2014; Griera, 2016; Burchardt, 2016). El gobierno catalán ha impulsado una política especialmente proactiva en esta área, y ha institucionalizado numerosos programas pioneros en la materia. En términos generales, el enfoque del gobierno catalán se ha encaminado a fomentar políticas de reconocimiento del pluralismo religioso y inclusivas con las minorías religiosas (Itçaina y Burchanti, 2007; Astor, 2014). Ahora bien, la existencia de una agenda política proactiva en esta materia no ha evitado el estallido de controversias públicas en torno a la religión. Hay dos polémicas que han sido especialmente relevantes: por un lado, la controversia sobre la apertura de lugares de culto ya mencionada y, por otro lado, los conflictos en torno al velo integral y su regulación en el ámbito local. En ambos casos, el origen de la controversia radica en la esfera local pero mientras el gobierno catalán y español han fomentado medidas para atenuar la crispación, las autoridades locales no siempre han trabajado en esta misma línea.

Hasta cierto punto, las políticas locales sobre el Islam se han visto condicionadas por la aparición de partidos políticos y movimientos de extrema derecha a nivel local. Destaca el surgimiento del partido Plataforma por Catalunya, que tiene un discurso notablemente antiislámico (Hernández-Carr, 2011). La aparición de este partido, a pesar que ha tenido relativo poco éxito en las elecciones locales, ha ejercido una influencia decisiva en desplazar el discurso de los partidos conservadores locales hacia posiciones más populistas. En cierto modo, el surgimiento de la controversia no se puede desvincular del contexto electoral ni de la competencia para ocupar la centralidad en el espacio político local. Cabe resaltar, además, que en algunos casos, como en Reus en 2005 y 2014, han surgido movimientos neofascistas que han ido más allá del ámbito del discurso y han llevado a cabo acciones violentas como pintadas racistas en las paredes de las mezquitas o el lanzamiento de cócteles molotov y otros artefactos. Estas acciones han dañado gravemente la convivencia local y han puesto de manifiesto la utilización de la retórica de la islamofobia por parte de la derecha populista y los movimientos neofascistas.

En Catalunya las controversias relativas a la apertura de lugares de culto se han producido sin interrupción, y más o menos de forma constante desde el año 2000 hasta la actualidad. Sin embargo, la polémica del velo integral estalla en 2010 y gana especial visibilidad entre 2010 y 2014. Inicialmente, la controversia se originó en Lleida, en mayo de 2010, cuando por iniciativa del alcalde Ángel Ros, la Asamblea Plenaria local de Lleida decidió aprobar 
una ordenanza para regular el uso del velo integral en los espacios públicos con multas de hasta 600 euros en caso de infracción. La prohibición fue ampliamente cubierta por la prensa local pero también estatal e internacional.

La aprobación de la ordenanza se llevó a cabo en medio del debate existente en Francia y Bélgica sobre esta misma temática, y se enmarcó, en gran parte, como una herramienta para detener el radicalismo islámico en los contextos locales. El debate de Lleida fue el catalizador para el surgimiento de nuevas propuestas para regular el uso del velo integral en muchas otras ciudades catalanas como Reus, Vendrell, Tarragona, Figueres o Manresa entre muchas otras. En medio de estos debates locales, el Partido Popular presentó una moción en el Parlamento Catalán para regular el velo integral a nivel catalán. La moción fue rechazada por mayoría simple. En 2013, Ciudadanos llevó de nuevo el tema al Parlamento catalán y exigió un cambio en la Ley de Libertad Religiosa, pidiendo que se reconociera el uso del velo integral como discriminatorio contra la mujer y como amenaza a la seguridad. La propuesta también fue rechazada. Es importante mencionar que, sorprendentemente, algunos de los partidos que votaron en contra de la regulación en el Parlamento Catalán, como el PSC (Partit dels Socialistes de Catalunya), estaban simultáneamente promoviendo la prohibición del uso del velo integral en muchas localidades.

Judicialmente, el proceso también es complejo y largo. Inicialmente, el TSJC (Tribunal Superior de Justicia de Catalunya) suspendió parcialmente la regulación de Lleida argumentando que era necesario clarificar el tema jurídicamente. Sin embargo, un año más tarde, en 2011, el TSJC en su veredicto final afirmó el derecho del Ayuntamiento de Lleida a regular el velo integral ${ }^{4}$. A partir de la iniciativa de una asociación musulmana local, el tema fue llevado al Tribunal Supremo Español que finalmente determinó que el Ayuntamiento de Lleida no tenía jurisdicción para regular sobre el uso del velo integral y añadió que no había motivos sociológicos que justificaran la prohibición ${ }^{5}$. Prohibición que, además, se consideraba que atentaba contra la libertad religiosa. Sin embargo, paradójicamente, esto

\footnotetext{
4 Ver: Sentencia T.S.J. Cataluña 489/2011, de 7 de junio. http://www.asesoriayempresas.es/jurisprudencia/JURIDICO/190774/sentencia-tsj-

cataluna-489-2011-de-7-de-junio-proteccion-jurisdiccional-de-los-derechos-fundame. Última consulta: 18/07/2016.

${ }^{5}$ Ver: Sentencia del Tribunal Supremo (Sala de lo Contencioso-Administrativo, Sección 7.a), de 14 de febrero de 2013 (ROJ STS 693/2013).
} 
no impidió que algunos ayuntamientos, como el de Reus, decidieran seguir adelante con la prohibición local del velo integral.

\section{LA PROHIBICIÓN DEL VELO INTEGRAL Y LA ORDENANZA DEL CIVISMO}

La historia de la regulación del velo integral en Reus es larga y enrevesada. Inicialmente, el debate surgió en medio de la controversia de Lleida y fruto del "efecto contagio". La cuestión se debatió en una sesión plenaria del Ayuntamiento de Reus en junio de 2010 - sólo un mes después que el Ayuntamiento de Lleida hubiera aprobado su prohibición-. La mayoría de los partidos políticos locales se mostraron a favor de prohibir el uso del velo integral en el espacio público pero la propuesta no fructificó porque no consiguieron ponerse de acuerdo en los términos utilizados para justificar la prohibición.

Por un lado, los partidos conservadores (CIU y PP) se mostraban partidarios de enmarcar la prohibición como un acto destinado a la protección de la dignidad de la mujer y aludiendo explícitamente al "burka" y al "niqab" como objeto de la regulación. Por otro lado, los partidos progresistas (PSC y ERC) - que estaban en el gobierno en ese momento- presentaron una propuesta para regular el uso del velo integral a través de una prohibición genérica contra la ocultación del rostro en los espacios públicos (y sin nombrar directamente al burka o al niqab). Según el edil socialista "la voluntad es evitar la estigmatización de la comunidad musulmana" y añadió: "si a alguien le interesa reglamentar que se vaya con la cara destapada en los edificios públicos, lo regulamos, pero no lo mezclemos con otros motivos religiosos" ${ }^{\prime \prime}$.

Debido a la imposibilidad de consensuar los términos de la prohibición, la moción no fue aprobada. Sin embargo, algunos meses después, en diciembre de 2010, el alcalde, por iniciativa propia, decidió aprobar un decreto prohibiendo el uso del velo integral en los edificios públicos de la ciudad. Ahora bien, los partidos conservadores no estaban satisfechos con la iniciativa: "No queremos un decreto, sino una ordenanza que amplíe la prohibición a la vía pública" 7 afirmaba uno de los concejales

\footnotetext{
${ }^{6}$ Ver:

http://sociedad.elpais.com/sociedad/2010/06/18/actualidad/1276812004_850215.html. Última consulta: 03/03/2016.

${ }^{7}$ Ver: http://elpais.com/elpais/2010/12/13/actualidad/1292231834_850215.html. Última consulta: 03/03/2016.
} 
conservadores. La ordenanza se convirtió en una realidad cuando el partido conservador catalán CIU ganó el gobierno de la ciudad en 2011 y decidió impulsar esta cuestión. Después de un largo proceso de debate, el Pleno aprobó la llamada "Ordenanza de civismo" en febrero de $2014^{8}$. El objetivo de la misma fue definido de la siguiente manera:

El objetivo principal de esta ordenanza es preservar el espacio público como lugar de convivencia, donde todas las personas puedan desarrollar en libertad sus actividades de libre circulación, ocio, encuentro, ocio y expresión, con pleno respeto a la dignidad y los derechos de los demás.

La ordenanza es un documento de más de 20 páginas que regula el comportamiento en la vía pública hasta el último detalle. Actividades como beber en la calle, mendigar, jugar a futbol o ir desnudo son cuidadosamente reguladas y, en la mayoría de casos, prohibidas. El artículo 10 de la ordenanza, titulado Normas de conducta prohíbe el uso del velo integral en los siguientes términos:

No está permitido permanecer en la vía pública ni acceder o permanecer en los autobuses municipales, en las instalaciones, equipamientos o locales donde se ofrezcan servicios municipales, a las personas que lleven velo integral, burka, niqab, pasamontañas, casco integral (salvo de lo previsto por la normativa general de circulación) $u$ otras vestimentas $o$ accesorios que impidan o dificulten la identificación?

\subsection{Prostitución, nudismo y velo integral en Reus}

Como ya hemos mencionado, Goffman (1971) entiende el espacio público como el escenario de las interacciones no focalizadas entre extraños, y como un lugar gobernado por la regla de la "inatención cortés". Según el sociólogo norte-americano esto es lo que permite a los transeúntes sentirse "seguros para centrarse en su actividad con sólo tener que prestar una atención periférica a comprobar la estabilidad del entorno" (Goffman, 1971: 283). Sin embargo, en ocasiones, el orden "normal" de la interacción se ve alterado cuando se producen

\footnotetext{
${ }^{8}$ La ordenanza fue derogada en julio de 2015 con una moción de la CUP y el PSC, con el apoyo de ERC y Ara Reus,. Los debates en la ciudad siguen vigentes. Ver: http://www.lavanguardia.com/local/reus/20150714/54433902308/reus-ordenanzacivismo.html. Última consulta: 18/07/2016.

${ }^{9}$ Ahora bien, la prohibición añade una excepción y afirma: "Esta prohibición no regirá en los supuestos de que se trate de actos festivos, tradicionales o culturales que se desarrollan en la vía pública o bien obedezca al ejercicio de una determinada profesión".
} 
situaciones disruptivas que rompen las expectativas de los actores. En cierto modo, el uso del velo integral es percibido como una "infracción" de los códigos que regulan la interacción en los espacios públicos y es la razón principal que aducen los defensores de la prohibición para justificar su posición.

Sin embargo, qué tipo de infracción ven en el porte del velo integral no es evidente a primera vista. Hay dos maneras distintas de abordar esta cuestión desde un punto de vista teórico: en primer lugar, la filosofía de Lévinas (1997) explora desde una perspectiva fenomenológica la importancia de mostrar el rostro. Según él, es en el encuentro "cara a cara" con el otro donde radica el fundamento de la ética. Lo que él llama la "desnudez indefensa" de la cara, y su potencia expresiva, parece afectarnos de forma pre-reflexiva y nos interpela; esta experiencia, según Lévinas da lugar a un sentimiento de identidad propia y, a la vez, de responsabilidad hacia los demás. En segundo lugar, nos podemos remitir a las aportaciones del sociólogo Alfred Schütz (1967) quien atribuye una importancia crucial a las interacciones "cara a cara" y basa la posibilidad de la experiencia de un nosotros intersubjetivo en los procesos de "idealización de la intercambiabilidad de los puntos de vista" y a la "idealización de la congruencia de los sistemas de significado". Para Alfred Schütz, como también lo será para Goffman (1956), la visibilidad de la cara del otro es, en general, no problemática y dada por descontado. En cierto modo, el rostro, como tal, sólo se convierte en "perceptible" o pasa a primer plano cuando la cara del otro no es visible $y$, por lo tanto, se rompen las expectativas en este sentido. Por lo tanto, desde la perspectiva de la teoría sociológica occidental, el velo integral introduce nuevas formas de interacción que perturban las suposiciones acerca de la reciprocidad visual de las perspectivas de los actores: uno ve sin ser visto.

El hecho de ver y ser visto en el espacio público tiene múltiples significados culturales y políticos. Significados que los actores involucrados en la prohibición movilizan con la voluntad de justificar su posición frente al velo integral. Así, los partidarios de la regulación argumentan que ver y mostrar el rostro es consubstancial a la civilización occidental y un requisito fundamental para el mantenimiento de la vida social. Según ellos, cuando nos cruzamos con el "otro" lo miramos a la cara para identificarlo y evaluar sus intenciones y estados de ánimo. Este "escaneo rápido" del rostro del otro genera el 
mínimo de confianza necesaria para poder sostener el orden de la interacción. Uno de los partidarios de la regulación lo expresaba en los siguientes términos:

Porque en nuestra cultura el rostro enseña la cara y la cara es
el reflejo del alma, (...) si tú estás contenta se ve en la cara, si
tienes odio lo reflejas en la cara. Tú puedes hablar conmigo y
por los ojos o por la expresión puedes saber que estoy
pensando y si lo que te digo es cierto o te estoy engañando, la
cara es eso, la seguridad y la perturbación de la tranquilidad.

Se considera que el hecho de taparse el rostro pone en peligro la confianza necesaria para la vida social y dificulta lo que Alfred Schütz (1967) Ilamó la "tipificación del otro"; entorpece la estandarización de la relación entre transeúntes, a la vez, que deviene fuente de sospecha e inseguridad. Se percibe, también, que el hecho de taparse el rostro es en sí mismo, un acto de auto-exclusión de la comunidad social y moral. Hecho que, los partidarios de la prohibición perciben como un acto potencialmente peligroso porqué, según ellos, revela la negativa de estas mujeres a reconocer los códigos tácitos que rigen el espacio público.

Se puede establecer un paralelismo entre los argumentos que movilizan los partidarios de la regulación a nivel local y los argumentos jurídicoinstitucionales que han emergido en los últimos años. Argumentos que se desarrollan en torno a tres ideas: la convivencia, la seguridad y la sinceridad. Por un lado, la Corte Europea de los Derechos Humanos en su veredicto a favor de la Ley francesa prohibiendo el porte del velo integral aludió a la importancia de favorecer la convivencia (afirmando, así, que el velo integral era un elemento que la dificultaba) ${ }^{10}$. Por otro lado, el veredicto europeo también mencionó la importancia de la identificación personal por cuestiones de seguridad. Se argumentó que el porte del velo integral entra en contradicción con las políticas de seguridad, y de control del terrorismo. Finalmente, el tercer argumento jurídico relevante en torno a la cuestión del velo integral y que también aducen los partidarios de la prohibición en Reus, es la cuestión de la sinceridad. El tema emergió en el marco de la petición de una testigo de testificar con burka en un juicio en Toronto. El tribunal no permitió a la

\footnotetext{
${ }^{10}$ Ver: Sentencia del Tribunal Europeo de Derechos Humanos (TEDH), de 1 de julio de 2014, sobre prohibición del velo integral en lugares públicos (Asunto S.A.S. C. Francia, núm.43835/2011, ECHR 2014).
} 
testigo testificar con velo integral ya que se consideró que la capacidad humana de evaluar la honestidad y sinceridad de los individuos está intimamente asociada con el hecho de ver y mirar el rostro del aquel que se juzga. En este sentido, la presidenta del tribunal Supremo de Justicia de Canadá afirmó: "Existe la presunción profundamente arraigada en nuestro sistema legal que ver la cara de un testigo es importante para un juicio justo, al permitir que un interrogatorio eficaz y la evaluación de la credibilidad"11.

Ahora bien, el concepto principal que los partidarios de la prohibición en Reus utilizaron para enmarcar su posición fue la de "perturbación de la tranquilidad". Según su opinión, la presencia de mujeres con velo integral perturba la tranquilidad del espacio público. En este contexto, la tranquilidad emerge no sólo como un estado emocional deseable de preservar en la vía pública sino también como algo a lo que uno tiene derecho como transeúnte. En esta línea uno de los defensores de la prohibición argumentaba: "así que por ejemplo cuando caminas por la calle de noche y ves a una persona que va con el rostro cubierto sientes que tu tranquilidad se ve perturbada. ¿Por qué? Porque en nuestra cultura nos enseñamos la cara".

Para él, ver y ser visto en el espacio público produce un sentimiento de familiaridad que da lugar a una sensación de tranquilidad. Es llamativo el hecho que la noción de "perturbación de la tranquilidad" ha estado asociada, mayoritariamente, a las molestias por ruidos generados por terceros - por ejemplo, para denunciar las actividades de pubs o discotecas nocturnas o vecinos ruidosos-. Sin embargo, el velo integral es, esencialmente, un acto "mudo", lo que muestra un giro semántico por el cual la idea de tranquilidad va más allá de una cuestión de decibelios y emerge como un "estado emocional" subyacente a la vida social en el espacio público. En este sentido, una de los interlocutoras afirmaba "en realidad no nos proponemos perseguir el uso del burka, simplemente estamos preservando nuestra convivencia" $y$, para conseguirlo era necesario, en sus propias palabras, una estrategia de "tolerancia cero". Vincula, así, la posición sobre el velo integral con un vocabulario heredado de la lucha contra el crimen, lo cual muestra como

11 Ver: http://www.theglobeandmail.com/news/national/witness-may-be-required-toremove-niqab-while-testifying-top-court/article6588243/?page=all. Última consulta: 02/03/2016. 
la percepción de la islamización del espacio urbano se articula con la percepción de inseguridad y criminalidad.

Ahora bien, desde nuestra perspectiva, la clave para entender la singularidad de la polémica del velo integral radica en el hecho que fue regulado conjuntamente con cuestiones como la desnudez en la calle, la prostitución y la mendicidad. El velo integral se incluyó dentro de una categoría más amplia de prácticas definidas como obscenas que se percibe que desafían los códigos de conducta establecidos. Cabe destacar que estos códigos contienen, también, ideas sobre las "emociones normales" y las emociones anormales -o indeseablesvinculadas a la interacción en el espacio público. Para los partidarios de la prohibición, la emoción principal que genera el velo integral es una sensación embarazosa (o de incomodidad) que se traduce en indignación y vergüenza. Por un lado, indignación por el hecho de percibir que esta es una práctica que erradica la propia individualidad y atenta contra los derechos de las mujeres. Y, por otro lado, vergüenza porqué se percibe que la existencia de personas con velo integral en la calle atenta contra la idea de un espacio público ideal definido en términos de tranquilidad, familiaridad y confianza. En un contexto como Reus, además, los actores conservadores perciben la presencia de personas con velo integral como muestra de la radicalización del islam y, en parte, como señales del propio fracaso para frenar o contrarrestar la imagen mediática de ser, conjuntamente con Tarragona, la cuna del islamismo radical en España.

Los pocos estudios antropológicos sobre las mujeres que deciden llevar el velo integral cuestionan la idea de a sumisión femenina frente al poder masculino (Párvez, 2011; Bracke y Fadil, 2011). Es más, estas antropólogas lo vinculan, de manera general a una forma de religiosidad híper-subjetiva e individualista fruto de una elección personal. Además, el hecho que muchas de estas mujeres sean conversas y solteras, atenta aún más contra el estereotipo dominante del burka como forma de "cárcel de ropa" y opresión. En esta línea, los abogados también llevaron a cabo estudios cualitativos basados en entrevistas con estas mujeres (Brehms et al., 2014). Ahora bien, este tipo de argumentos son completamente rechazados por los interlocutores conservadores. Así, una de nuestras entrevistadas afirmaba: "la teoría de que lo lleven voluntariamente no me la creo". El hecho de escoger llevar un burka aparece como totalmente ininteligible y irracional. Además, cuando el 
argumento principal de la prohibición se articula en torno a la idea de que es una práctica incompatible con el régimen emocional del espacio público el hecho que sea fruto, o no, de la elección personal pierde relevancia. La prohibición del velo se justifica por el hecho que genera vergüenza, miedo y ansiedad. Una vergüenza, en cierto modo comparable, a la que produce la desnudez (Lehumuskallio, 2013) en el espacio público. Una de las interlocutoras afirmaba: "Un niño no tiene por qué ver que esta señora va totalmente tapada en una cárcel de ropa", de la misma manera que afirma que los niños no deben ser expuestos a la desnudez. De este modo, la prohibición del porte del velo integral en plazas y parques es considerada como una forma de proteger los sentimientos de los niños, y otros transeúntes, de un posible prejuicio emocional. Desde este punto de vista, y sin dejar de ser símbolo del islam radicalizado, la polémica del velo integral se sitúa más allá de la dicotomía laico-religioso y aparece en continuidad con la regulación de la desnudez, la mendicidad o la bebida en la calle. Lo que todas estas prácticas "disruptivas" tienen en común es que ponen en cuestión lo que Goffman llama las "apariencias normales" y amenazan el orden de la interacción. Desde esta perspectiva, la prohibición del velo integral emerge como consecuencia lógica de la política destinada al "encubrimiento de defectos visuales y elementos antiestéticos (para mejorar) la estética del espacio público" (Cook and Whowell, 2011: 260).

Sin embargo, resulta importante señalar que la "normalidad" - o la ausencia de ella - no es la razón última o única para explicar la prohibición de estas prácticas. La calificación de una práctica como normal -o anormal- implica también la realización de un juicio de carácter moral. La mirada de los transeúntes no es neutral sino mediada por unas determinadas memorias urbanas, aspiraciones políticas y imaginaciones sobre el futuro. En este sentido, la clasificación del porte integral como una "práctica indeseable" se narra a través de un repertorio específico de argumentación que bebe de una concepción moral particular. Es decir, las razones que se aducen para justificar la inclusión del velo integral en la ordenanza responden a un régimen de justificación de orden diferente al que concierne, por ejemplo, a la inclusión de la mendicidad. En cierto modo, el discurso contra el velo integral contiene y condensa ideas, metáforas y narraciones que resuenan poderosamente con las narrativas ideológicas conservadoras sobre la inmigración y el islam. 
De este modo, una de las impulsoras de la prohibición, justifica la inclusión del velo integral en la ordenanza en estos términos: "la finalidad era dar un mensaje, un mensaje social, para la gente de Reus y para la gente que había venido de fuera, la inmigración tiene que estar integrada, legal y ordenada, no puede ser que valga todo" y añadió: "el burka es el signo más visible y más radical de esta Islam (...) y no vamos a tolerar esto, tenemos que poner algunos límites". En este sentido, el velo integral puede ser considerado como un recurso simbólico disponible en la arena global que puede ser utilizado de manera estratégica para hacer política en la escena local. La hipervisibilidad del velo integral en la personificación de los temores de islamización, y su capacidad para despertar fuertes (y viscerales) emociones otorga mayor visibilidad pública (y eficacia) a la prohibición. Hasta cierto punto, como afirma Mazzarella: "Cualquier proyecto social que no se impone por la fuerza por sí sola debe ser afectivo [emotional] con el fin de ser eficaz" (2009: 299).

Sin embargo, una vez más, al analizar el discurso de los defensores pro prohibición es importante ir más allá de la dicotomía religioso-secular. Los defensores de la prohibición construyen su argumento a partir de la negación que el porte del velo integral se pueda considerar como una práctica religiosa. Afirman, además, la necesidad de marcar una frontera clara entre el uso del velo (hijab) y del velo integral (burka o niqab). Mientras defienden que el porte del hijab es una práctica religiosa legitima que debe respetarse en aras a la libertad religiosa, se niega con vehemencia la naturaleza religiosa del velo integral. En esta línea una de las entrevistadas afirma: "lo estuvimos estudiando, el burka es pre islámico, no tiene nada que ver con el Islam, me parece que era del desierto de Pakistán, en su momento, que era por el tema de los vientos y de la arena". Es decir, detectamos un esfuerzo consciente por parte de los defensores de la prohibición en ubicar la controversia más allá de la gramática religiosa-secular.

Es interesante mostrar que la mayoría de los impulsores de la regulación a nivel local no se identifican como defensores de la laicidad, ni se sienten cómodos con los repertorios clásicos de argumentación laicistas o secularistas. De hecho, la mayoría de ellos se declaran públicamente católicos, cuentan con el apoyo de los votantes católicos y perciben a los "actores laicista" como parte de sus adversarios, y no sus aliados. Por lo tanto, defienden el hijab como una práctica respetable de piedad 
mientras denuncian el velo integral como una práctica ajena que, desde su perspectiva, contamina la "buena" reputación del Islam. Hasta cierto punto, el hecho de negar el carácter religioso del velo integral se revela como una estrategia para proteger el orden negociado existente en torno a la religión. La voluntad es mostrar la compatibilidad entre la religión y el laicidad y, por lo tanto, fomentar una imagen de la religión (ya sea católica o musulmana) como compatible con la sociedad "moderna" occidental. La "ininteligibilidad" (Amiraux, 2013) que produce el velo integral, y las emociones viscerales que engendra podría poner en peligro el postulado acerca de la convivencia armoniosa (y la adaptabilidad) entre los ciudadanos religiosos y seculares en la sociedad contemporánea. Así, paradójicamente, la prohibición del velo integral se entiende mejor como un acto dirigido a "proteger" - o incluso redimirla religión en tiempos seculares que como un intento laicista de prohibir la religión en el espacio público. Sin duda, es importante situar estos resultados dentro del contexto más amplio de los debates europeos sobre la laicidad en las que los significados de este término son fundamentalmente ambiguos. Es decir, el argumentario laico puede servir tanto para justificar medidas que restringen la presencia pública de la religión como para defender versiones expansivas del reconocimiento de la diversidad religiosa.

\subsection{En defensa del espacio público: activismo, laicismo y cosmopolitanismo}

La campaña de oposición a la regulación del velo integral se fraguó y articuló alrededor de la defensa de una determinada noción de espacio público $y$, en buena medida, dejó al margen las cuestiones relativas a la religión. Es decir, el análisis del discurso de los actores sociales y políticos que se opusieron a la prohibición muestra que, a pesar de unas pocas excepciones, la mayoría de actores justificaron su negativa a la prohibición a partir del argumento que esta vulneraba el carácter abierto, cosmopolita y público del espacio público. Uno de los principales actores que se opuso a la ordenanza fue una asociación cultural llamada Carrutxa dedicada a la investigación y la difusión del patrimonio etnológico y la cultura popular. A parte de las actividades de investigación, Carrutxa organiza numerosos actos de cultura popular en la vía pública y promueve una visión del espacio público como espacio de interacción y convivencia. Su oposición se articuló, principalmente, a través de tres argumentos concretos. 
Por un lado, pusieron de manifiesto que la ordenanza contribuía a profundizar la tendencia a la privatización y a la securización del espacio público. La hiperregulación de las actividades legítimas -y especialmente no legítimas - en la vía pública va en detrimento, según su visión, de la construcción de la calle como espacio de interacción y de integración. Además, según su punto de vista, la ordenanza se podía convertir, indirectamente, en un factor de discriminación hacia la población recién llegada. Población que, por circunstancias culturales, y seguramente también socioeconómicas, hacen un uso más extensivo del espacio público. En este sentido, un activista de Carrutxa señalaba:

Nos dimos cuenta que el espacio público tiene un elemento discriminatorio porque las personas que utilizan los espacios públicos con mayor frecuencia son los migrantes y otras personas pobres. Por lo tanto, es perverso decir que con un burka no puede utilizar los parques infantiles o las plazas, o no se puede hacer esto o aquello.

Por otro lado, consideraban que la aprobación de la ordenanza abría la puerta a la regulación, o prohibición de los actos de cultura popular que se realizan en la calle. Actos, además, que en ocasiones incluyen, también, el cubrimiento de la cara y otras acciones que podian ser consideradas como "incívicas" por la normativa (como comer en la calle, organizar conciertos...). Si bien la ordenanza contemplaba la excepción por motivos culturales, ellos señalaron la hipocresía de definir determinadas actividades como "legítimas" y otras como "ilegítimas" en base a la argumentación del arraigo histórico-cultural.

Finalmente, los activistas de Carrutxa se opusieron a la ordenanza en tanto que consideraban que se utilizaba esta cuestión como punta de lanza para legitimar una estrategia de control y homogenización del espacio público que iba en contra la idea de la calle como espacio de libertad. En cierto modo, lo que los interlocutores de Carrutxa relatan, y que también enfatizaran los activistas de la CUP quienes convergirán en su oposición a la ordenanza, es que los políticos locales utilizaron la criminalización del velo integral como estrategia para impulsar una agenda política conservadora en relación al espacio público.

Para estos activistas, la problematización del velo integral obedecía a una estrategia de creación de "pánico moral" que conllevaba la difusión de un discurso que presentaba el velo integral como un problema de grandes magnitudes al que era necesario hacer frente de manera inminente y 
contundente. Para estos actores, este proceso es paralelo a lo que el sociólogo sud-africano Stanley Cohen Ilama la creación de "pánico moral", al cual define como "una condición, episodio, persona o grupo de personas emergen y son definidos como una amenaza para los valores e intereses de la sociedad" (1972: 9). La importancia de los medios y los políticos locales en construir la problemática del burka como una batalla moral urgente y preocupante creó un clima propicio al consenso en torno a una regulación que iba mucho más allá de esta cuestión. En cierto modo, como enfatiza Garland (2008) la creación de un clima de pánico moral acostumbra a construirse en forma de hostilidad desproporcionada hacia un fenómeno que divide la población entre "ellos" y "nosotros".

En definitiva, la oposición de Carrutxa, y también de la CUP, se articuló alrededor de la denuncia del uso -y abuso- de la cuestión del "burka" para impulsar un amplio abanico de regulaciones que iban mucho más allá de esta cuestión. Carrutxa publicó un manifiesto que es muy ilustrativo de este punto de partida y que exponía lo siguiente:

(...) la ordenanza crea debates sobre aspectos irrelevantes de la vida ciudadana. Probablemente, en Reus, hay muchas más personas que deben circular con la cara tapada por una máscara contra el polvo, por razones de salud, que mujeres que llevan burka por una discutible interpretación de unas creencias religiosas. La formulación de una idea tan sencilla como que todos podamos identificarnos o ser identificados cuando haya una necesidad real - ireal! - de ser conocido deviene motivo de un debate que aviva los sentimientos xenófobos, los prejuicios contra las personas venidas de otros países, con argumentos y sobre hechos que nada tienen que ver con el hecho de llevar el rostro tapado y que afectan a muchas más personas que un grupo de mujeres concretas. Pretender que con esta formulación, la ordenanza quiere fomentar la convivencia resulta, como mínimo, sorprendente ${ }^{12}$.

La implicación de los activistas de izquierda en la cuestión del velo integral, responde a la voluntad de defender una determinada concepción del espacio público. La ordenanza se sumaba a una amplio abanico de acciones políticas - como la eliminación de los bancos públicos a favor de más restaurantes o la substitución de espacios verdes por entornos cimentados - que eran percibidas como resultado de una creciente

${ }_{12}$ Extraído de: http://www.carrutxa.cat/ftp/355_20150716074950.pdf. Última consulta: 15/02/2016. 
privatización y comercialización del espacio urbano. Desde su punto de vista, la prohibición del velo integral no se podía desligar de este contexto.

En cierto modo, es preciso reseñar cómo las denuncias de los activistas anti regulación ponen de relieve que la normativa vulnera el principio que Lyn H. Lofland (1989) denomina como "civilidad con la diversidad". El antropólogo Isaac Marrero lo define de la siguiente manera: "el urbanista mostrará, en general, tolerancia hacia la gran diversidad de 〈fachadas〉 con las que se cruza o comparte un espacio. Este actuar 〈decentemente〉 tendría que ver con la 'libertad' atribuida a los entornos urbanos, el juicio y la censura de las apariencias es mucho más débil" (2009: 82). La mayoría de antropólogos urbanos defienden que esta "civilidad" va vinculada a una cierta indiferencia hacia la diversidad (Delgado, 1998). Desde esta perspectiva resulta inteligible la posición de los activistas de izquierda en contra la prohibición: no se trata de la defensa a una determinada prenda religiosa ni de un clamor a favor de la libertad religiosa sino de la reivindicación del derecho a la indiferencia y a la comprensión de la vida urbana como un espacio de libertad.

De hecho, todos los actores entrevistados que se oponen a la prohibición hacen hincapié en su enfoque laico y en su distancia de la religión. En su gran mayoría se identifican con posiciones laicas - o incluso laicistas- y muestran su negativa a leer su oposición a la ordenanza en términos de defensa de la religión. Los activistas de la CUP formularon su posición en este sentido de una forma mucho más clara. Así, a pesar que se opusieron de forma vehemente a la prohibición del velo integral también añadieron que esto no quería decir que formaran una alianza con las organizaciones musulmanas. En este sentido, afirmaban:

No nos sentaremos con ellos para elaborar una estrategia conjunta. Y no vamos a hacerlo, porque tampoco colaboramos con las cofradias católicas $u$ otras asociaciones religiosas. Es decir, somos ateos, o al menos seculares y no vamos a hablar ni con los cristianos, ni con los musulmanes como tales. Nuestros interlocutores son los ciudadanos de Reus en su conjunto y no como miembros de organizaciones religiosas.

Además, añadían "Mezclar estas cosas no ayuda a nadie" y es que es importante señalar la dificultad de construcción de un relato capaz de articular y vehicular la ininteligibilidad que produce el velo integral entre la población $(y$, especialmente, en el contexto de creación de una situación de "pánico moral"). De alguna manera, su oposición a la prohibición del 
velo integral parte de una concepción de espacio público donde "aprender a no prestar demasiada atención a los demás derivado del inevitable anonimato es también fundamento mismo de la libertad urbana, el cosmopolitismo" (Marrero, 2009: 77).

\section{CONCLUSIONES}

El análisis de la controversia sobre el velo integral revela que, como Tonkiss observa "la calle (...) no es un espacio abstracto de encuentro social, sino una maraña de códigos sociales y contactos potencialmente peligrosos" (2005: 71). De una manera similar Goffman señaló que si bien las calles de la ciudad proporcionan un entorno en el que la confianza mutua se muestra de forma rutinaria entre extraños (1963: 17), hay múltiples ocasiones en que surgen cuestiones que desafian el orden "normal" de interacción y la matriz moral que lo regula.

La naturaleza conflictiva de la polémica del velo integral radica principalmente en el hecho de que contradice las reglas de la interacción urbana basadas en una concepción determinada de orden social marcado a su vez, por cuestiones de clase, etnia y género-. Los defensores de la prohibición perciben el velo integral como una ruptura de la organización ritual de los encuentros sociales. En cierto modo, el hecho de mostrar el rostro es elevado a "indicio universal de civilización" (Fournier, 2013) y se considera que la "ciudadania" también tiene que mostrarse corporalmente. En este contexto, el uso del velo integral emerge como un signo de un estigma tribal (Goffman, 1963: 4). Un estigma que se define como el conjunto de las normas derivadas de la imagen cultural dominante y que sirve como estándar para estigmatizar los sujetos que no cumplen lo esperado. El estigma, además, recae especialmente sobre las mujeres que mientras son presentadas como víctimas sin agencia son convertidas en chivos expiatorios y en símbolo visible de lo "no asimilable" (Vasallo, 2014). Ahora bien, este proceso de estigmatización no se produce, solamente, alrededor del velo integral. Los discursos de los partidarios de la prohibición vinculan el velo integral a tres gestos corporales: mostrar el rostro, dar la mano y beber vino. Se utilizan estas tres cuestiones como gestos simbólicos que sirven para marcar la frontera entre "nosotros" y "ellos", a la vez que reafirman los límites de la asimilación. Son leídos como gestos que marcan una "deferencia insuficiente" (Goffman, 1956) hacia la sociedad en la que se inscriben y por lo tanto son conjurados como fuente de peligro para la comunidad moral. 
Como hemos argumentado, el análisis de la controversia sobre el velo integral muestra que para comprender el surgimiento y evolución de la problemática sobre la cuestión es necesario ir más allá del binomio religión-secularidad. Por un lado, el análisis muestra que, a diferencia de lo que ha sucedido en otros contextos geográficos, en el caso de Reus la prohibición no se ha justificado a partir de un repertorio de inspiración laicista sino más bien al contrario. Es el deseo de proteger una concepción determinada de la religión como compatible con la modernidad la que favorece la articulación de una posición contraria al velo integral. En este sentido, resulta interesante señalar la plasticidad del repertorio argumentativo sobre la laicidad que cristaliza en posiciones ideológicas, sociales y culturales distintas en diferentes contextos. Señalar, también, y como ya hemos hecho en otro contexto (Burchardt et al., 2015) que la controversia provoca una re-articulación de los ejes izquierda-derecha, a la vez que reformulaciones y múltiples contestaciones en el seno del feminismo. La confrontación entre laicistas y confesionalistas y las motivaciones para la prohibición de su uso en el espacio público no se explican solamente por una supuesta oposición entre el islam y el estado secular. Es decir, en grandes rasgos, no podemos afirmar que esta sea una problemática sobre la identidad entre partidarios de la religión y sus detractores. De este modo, si bien la mayor parte de la literatura académica existente se focaliza en examinar la compatibilidad (o no) del velo integral con determinadas concepciones de la laicidad, nuestra investigación pone de relieve que para comprender el origen y la naturaleza del conflicto es necesario entenderlo como consecuencia de la existencia de diferentes concepciones sobre el espacio urbano y sus usos. De este modo, la micropolítica de la controversia se entiende mejor si se ve a la luz de la naturaleza excluyente del espacio público contemporáneo en vez de cómo un enfrentamiento sobre los límites de la libertad religiosa.

\section{BibLIOGRAFÍA}

Amiraux, V. (2013). The 'illegal covering' saga: what's next? Sociological perspectives. Social Identities, 19(6), 794-806.

Amirian, N., \& Zain, M. (2009). El islam sin velo. Barcelona: Planeta.

Arlettaz, F. (2015). Religión, esfera pública, mundo privado. Zaragoza: Prensas de la Universidad de Zaragoza. 
Astor, A. (2011). Mobilizing against Mosques: The Origins of Opposition to Islamic Centers of Worship in Spain. Tesis doctoral. Michigan: University of Michigan.

Astor, A. (2014). Religious governance and the accommodation of Islam in contemporary Spain. Journal of Ethnic and Migration Studies, 40(11), 1716-1735.

Becci, I., Burchardt, M., \& Giorda, M. (2016). Religious super-diversity and spatial strategies in two European cities.Current Sociology, DOI: $10.1177 / 0011392116632030$.

Berger, P. L. (1999). The Desecularization of the World: Resurgent Religion and World Politics. Washington D.C.: Wm. B. Eerdmans Publishing.

Bracke, S., \& Fadil, N. (2011). "Is the headscarf oppressive or emancipatory?" Field notes from the multicultural debates. Religion and Gender, 2(1), 36-56.

Brems, E. (Ed.) (2014).The experiences of face veil wearers in Europe and the law. Cambridge: Cambridge University Press.

Burchardt, M. (2016). Recalling modernity: how nationalist memories shape religious diversity in Quebec and Catalonia. Nations and Nationalism. DOI: $10.1111 /$ nana.12233.

Burchardt, M., \& Höhne, S. (2016). The infrastructures of diversity: Materiality and culture in urban space-an introduction. New Diversities, 17(2), 1-13.

Burchardt, M., Griera, M., \& García-Romeral, G. (2015). Narrating Liberal Rights and Culture: Muslim Face Veiling, Urban Coexistence and Contention in Spain. Journal of Ethnic and Migration Studies, 41(7), 1068-1087.

Casanova, J. (1994). Public religions in the modern world. Chicago: University of Chicago Press.

Cohen, S. (1972). Moral panics and folk devils. London: MacGibbon \& Kee.

Cook, I. R., \& Whowell, M. (2011). Visibility and the policing of public space. Geography compass, 5(8), 610-622.

Cox, H. (1965). The Secular City. US: Collier Books.

Delgado, M. (1998). Diversitat i integració. Lógica y dinámica de les identitats a Catalunya. Barcelona: Empúries.

Díaz-Salazar, R. (2007). Democracia laica y religión pública. Madrid: Taurus. 
Fadil, N. (2014). Asserting State Sovereignty. The Face veil ban in Belgium. In E. Brems (Ed.), The Experiences of face veil wearers in Europe and the Law (pp. 251-262). United Kingdom: Cambridge University Press.

Ferrari, A., \& Pastorelli, S. (Eds.) (2013). The burqa affair across Europe: Between public and private space. Farnham: Ashgate Publishing.

Fournier, P. (2013). Headscarf and burqa controversies at the crossroad of politics, society and law. Social Identities, 19(6), 689-703.

Garfinkel, H. (1967). Studies in ethnomethodology. New Jersey: Prentice Hall.

Garland, D. (2008). On the concept of moral panic. Crime, Media, Culture, 4(1), 9-30.

Grillo, R., \& Shah, P. (2012). Reasons to Ban? The Anti-Burqa Movement in Western Europe. MMG Working Paper, 12(05).

Goffman, E. (1956). The nature of deference and demeanor.American Anthropologist,58(3), 473-502.

Goffman, E. (1963). Behavior in public places: Notes on the social organization of gatherings. New York: Free Press New York.

Goffman, E. (1971). Relations in public: Microstudies of the social order. London: Allen Lane.

González de Requena, J. A. (2012). El espíritu público en la era democrática: Tocqueville acerca de la esfera pública y de la cultura. Estudios de filosofía práctica e historia de las ideas, 14(2), 45-56.

Griera, M. (2016). The governance of religious diversity in stateless nations: the case of Catalonia. Religion, State and Society, 44(1), 13-31.

Griera, M., Martínez-Ariño, J., Clot-Garrel, A., \& García-Romeral, G. (2015). Religión e instituciones públicas en España. Hospitales y prisiones en perspectiva comparada. Revista Internacional de Sociologia, 73(3). DOI: http://dx.doi.org/10.3989/ris.2015.73.3.e020.

Habermas, J. (1962). Strukturwandel der Öffentlichkeit. Untersuchungen zu einer Kategorie der bürgerlichen Gesellschaft. Frankfurt/Main: Suhrkamp.

Habermas, J. (2006). Religion in the public sphere. European Journal of Philosophy, 14(1), 1-25.

Hernández-Carr, A. (2011). El largo ciclo electoral de Plataforma per Catalunya: del ámbito local a la implantación nacional (2003-2011). Barcelona: Working Papers, Institut de Ciències Polítiques i Socials.

IDESCAT (2015). Dades. Demografia i Societat. Accesible en: www.idescat.cat. Última consulta: 03/03/2016. 
Itçaina, X., \& F. Burchianti. (2007). Local authorities and interfaith dialogue in Spain. In Council of Europe (Ed.), Gods in the city. Intercultural and inter-religious dialogue at local level (pp. 99-126). France: Local \& Regional.

Joppke, C. (2010). Veil. Mirror of identity. Londres: Polity Press.

Lehmuskallio, A. (2013). Banning public nudity: images of bodies as sites of contested moral values. JOMEC Journal Journalism, Media and Cultural Studies, 4, 1-20.

Lévinas, E. (1987). Totalidad e infinito: ensayo sobre la exterioridad. Salamanca: Ediciones Sígueme.

Lofland, L. H. (1989). Social Life in the Public Realm. A Review. Journal of Contemporary Ethnography,17(4), 453-482.

Marrero, I. (2009). La producción del espacio público. Fundamentos teóricos y metodológicos para una etnografía de lo urbano. (Con)textos: revista d'antropologia i investigació social, 1, 74-90.

Martínez-Ariño, M., Garcia-Romeral, G., Ubasart, G., \& Griera, M. (2015). Demonopolization and dislocation: (re-)negotiating the place and role of religion in Spanish prisons. Social Compass, 62(1), 3-21.

Mazzarella, W. (2009). Affect: What is it Good for?. In S. Dube (Ed.), Enchantments of modernity: Empire, nation, globalization (pp. 291309). India: Routledge.

Motilla, A. (2013). The Burqa Affair in Spain: Legal Perspectives. In A. Ferrari \& S. Pastorelli (Eds). The Burqa Affair Across Europe: Between Public and Private Space (pp. 127-141). Farnham: Ashgate Publishing.

Párvez, Z. F. (2011). Debating the Burqa in France: the Antipolitics of Islamic Revival. Qualitative Sociology, 34(2), 287-312.

Schütz, A. (1967). The phenomenology of the social world. Illinois: Northwestern University Press.

Schütz, A. (1974).Der sinnhafte Aufbau der sozialen Welt: Eine Einleitung in die verstehende Soziologie. Frankfurt/Main: Suhrkamp.

Selby, J. A. (2011). French secularism as a 'guarantor' of women's rights? Muslim women and gender politics in a Parisian banlieue. Culture and Religion, 12(4), 441-462.

Tonkiss, F. (2005). Space, the city and social theory: Social relations and urban forms. Cambridge: Polity Press.

Vasallo, B. (2014). Velo integral: el feminismo como exclusión. Pikara. Disponible en: http://www.pikaramagazine.com/2014/12/velo- 
integral-el-feminismo-como-exclusion/. Última consulta: 03/03/2016.

Wohlrab-Sahr, M., \& Burchardt, M. (2012). Multiple secularities: Toward a cultural sociology of secular modernities. Comparative Sociology, 11(6), 875-909. 